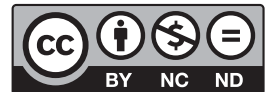

Estudos Teológicos foi licenciado com uma Licença Creative Commons Atribuição - NãoComercial - SemDerivados 3.0 Não Adaptada

http://dx.doi.org/10.22351/et.v60i2.4093

\title{
REAlidAdes do MAL: OBSERVAR A PANDEMIA PELO DESAMPARO, O SOFRIMENTO INTENCIONAL E A NEGLIGÊNCIA DA MORTE ${ }^{1}$
}

\author{
Forms of evil: observing the pandemic from helplessness, \\ intentional suffering and neglect of death
}

\section{Douglas Ferreira Barros ${ }^{2}$}

Resumo: O objetivo do artigo é pensar o mal em sua relação com a morte e o desaparecimento. Partimos do estudo de Paul Ricoeur que toma o mal como desafio à filosofia e à teologia. Propomos destacar a relação entre alguns aspectos que envolvem a compreensão ricoeuriana do mal e o posicionamento discursivo público de autoridades governamentais do Brasil acerca dos mortos pela pandemia de Covid-19 ou coronavírus. Nossa análise mostra como a múltipla compreensão ricoeuriana acerca do mal - tanto em sua acepção teológica como naquela filosófica - nos dá elementos para uma avaliação do posicionamento discursivo dessas autoridades em relação à morte e aos mortos pela doença na pandemia. Tomaremos como objeto da análise as declarações de autoridades governamentais publicadas em diferentes meios - jornais, portais de notícias, principalmente. Como método de trabalho, observaremos, em paralelo à qualificação ricoeuriana do mal, o posicionamento discursivo de tais autoridades públicas acerca da morte e dos mortos. Pretendemos mostrar na conclusão que a luta contra o mal pressupõe, tanto em termos filosóficos como teológicos, a atuação ética e política contra a violência, o desamparo e a negligência à vida humana.

Palavras-chave: Mal. Sofrimento intencional. Desaparecimento. Morte. Pandemia do coronavírus.

Abstract: The article aims to think of the evil in its connection with death and disappearance. We will use as theoretical reference Ricoeur's conference in which he presents the evil as a challenge to philosophy and theology. We intend to show the connection between numerous aspects related to the Ricoerian conception of evil and the Brazilian government officials' public discourse about those killed by the current Covid-19 pandemic. Our analysis shows how the Ricoeurian understanding of evil -

1 O artigo foi recebido em 08 de julho de 2020 e aprovado em 23 de setembro de 2020 com base nas avaliações dos pareceristas ad hoc.

Este texto é resultado de pesquisa financiada pelo CNPq, processo 428541/2016-0, instituição a qual agradeço especialmente. Sou grato, também, aos colegas do Grupo de Pesquisa Ética, Política e Religião: questões de fundamentação (CNPq-PUC-Campinas).

2 Doutor. PUC-Campinas. E-mail: douglasfbarros@gmail.com 
both in its theological and philosophical sense - gives us elements for an evaluation of this discursive position. The object of analysis will be the government authorities statements published in different media - mainly newspapers, news websites. As a method of research, we will observe, in parallel to the Ricoeurian qualification of the evil, the discursive position of such public authorities regarding death and the dead. We intend to show as a conclusion that both in philosophical and theological terms the fight against evil supposes an ethical and political action against violence, helplessness, and the neglect of human life.

Keywords: Evil. Intentional suffering. Disappearance. Death. Coronavirus pandemic.

\section{Introdução: realidade do mal como desafio teológico e filosófico}

O objetivo do artigo é pensar o mal para além de sua acepção moral e tomá-lo como um problema filosófico e teológico que diz respeito à prática intencional do sofrimento. Ricoeur entende que o sofrimento e a morte exprimem o mal como um elemento que é consequência de um ato intencional. Assim entendido, o mal não é resultante apenas de um desvio moral, mas é produto da intenção de atingir e levar o sofrimento, negligenciar a morte. Orientada pela reflexão ricoeuriana, a intenção do artigo é observar a materialidade do mal na atuação governamental para minimizar os efeitos da pandemia do coronavírus. É possível mostrar que a intenção e as práticas para efetuar o desaparecimento dos mortos e da morte, em sentido amplo, são efeitos e exprimem a prática do mal.

"De onde vem o mal?"3, perguntava-se Paul Ricoeur por ocasião da conferência proferida na Faculdade de Teologia de Lausanne em 1985. Para a filosofia e a teologia, ele constata que a resposta à indagação sobre a realidade do mal constituía um desafio nada simples. A dificuldade poder-se-ia aferir pela importância que atribuíram ao tema filósofos, desde a antiguidade clássica, e teólogos, desde os mais remotos estudiosos dos livros sagrados. Tanto pela filosofia como pela teologia, o exame do mal envolvia a resposta sobre sua existência, tema que se estenderia à indagação acerca de quem o poderia ter criado. Como poderia o Criador, todo-poderoso e absolutamente bom, ser a causa eficiente do mal?

O problema da atribuição de criação do mal a Deus faz da teodiceia um trabalho de combate, diz Ricoeur, em "favor da coerência e contra a proposta de que apenas duas das proposições são compatíveis", a saber: "Deus é todo-poderoso; Deus é absolutamente bom; o mal existe" . A questão transborda da mera indagação filosófica, mas pode ser tomada como um problema ontoteológico, diz o autor. A dificuldade consiste em que a tarefa de se pensar a realidade do mal ou, em termos ontoteológicos, tal como assinalado por Ricoeur: "de pensar Deus e o mal diante de Deus"s, pode não

\footnotetext{
RICOEUR, Paul. El mal: un desafío a la filosofía y a la teología. Buenos Aires: Amorrortu, 2007. p. 36.

RICOEUR, 2007, p. 22.

RICOEUR, 2007, p. 22.
} 
se esgotar com a investigação racional ou com uma proposta de solução ao princípio de não contradição.

O aspecto notável da estratégia analítica desse filósofo está em reconhecer que a resposta ao "enigma do mal" envolve pelo menos localizar seu enraizamento em fenômenos diversos como o pecado, o sofrimento e a morte. Dizer que o mal como um problema filosófico e teológico ultrapassa os limites da dimensão moral nos abre assim à possibilidade de pensá-lo como elemento que não restringe o julgamento sobre as ações humanas à avaliação sobre o erro, a falha e a imputação da culpa pessoal, e posterior obrigação de aceitação resignada da punição.

Ainda que o sofrimento fosse para alguns - em sintonia com o pensamento de Agostinho - uma consequência punitiva do desvirtuamento moral, Ricoeur defende que se trata de uma dimensão que nos remete a outra sorte de indagações. O sofrimento e a morte seriam realidades que exprimem o mal não apenas no registro de um ato que é cometido, mas, principalmente, como resultante de um ato que atinge e é recebido por outro. Trata-se de abordar o mal não como falta daquele que age, escolhe, decide, um desvio na rota em direção à verdade, e sim de compreendê-lo como consequência de agressão, violação intencional, que inflige o mal do sofrimento até o ponto de se levar a vítima até a morte. Ele afirma:

Considerado igualmente no seu sentido estrito, o sofrimento distingue-se do pecado por características opostas. Em contraste com a imputação, que centra o mal moral num agente responsável, o sofrimento enfatiza o fato de ser essencialmente sofrido: nós não o causamos, ele nos afeta. Isso explica a espantosa variedade das suas causas: adversidade da natureza física, doença e incapacidade do corpo e da mente, aflição causada pela morte de entes queridos, perspectiva aterradora da própria mortalidade, sentimento de indignidade pessoal, etc.; por oposição à acusação, que denuncia um desvio moral, o sofrimento é caracterizado como puramente contrário ao prazer, como não prazer, ou seja, como uma diminuição da nossa integridade física, psíquica ou espiritual. Finalmente, e acima de tudo, o sofrimento opõe-se à reprovação ao lamento; porque, se a culpa torna o homem culpado, o sofrimento faz dele uma vítima: contra este grito de lamento ${ }^{6}$.

O sofrimento não habita o mesmo locus do pecado, mas ambos compõem a constelação de elementos que constituem o mal. A imputação do pecado a alguém resulta do julgamento e da constatação do erro já cometido; o sofrimento supõe certa condição de passividade e desconhecimento por aquele que é atingido em um ato: o sofrimento enfatiza o fato sofrido, destacou Ricoeur.

No mundo judaico-cristão, tende-se a circunscrever o mal à órbita do erro, do desvio, da falta. Enquanto expressão última do mal, “[...] o pecado, tal como os pensadores cristãos o concebem, faz de quem o comete um adversário de Deus e um rebelde" " A incidência ou o reconhecimento da culpa por aquele que erra visa ao fortalecimento dos freios internos aos possíveis futuros atos desviantes; o arrependimen-

6 RICOEUR, 2007, p. 24-25.

7 GILSON, Étienne. O Espírito da Filosofia Medieval. São Paulo: Martins Fontes, 2006. p. 414. 
to libera o agente da penalização causada pelos atos desviantes. Toda a relação entre mal, pecado, culpa, pena e arrependimento diz respeito aos atos de quem se move por uma intenção prévia.

Mas inúmeras são as figuras assumidas pelo mal no contexto mitológico, filosófico e teológico do Ocidente. ${ }^{8}$ Ricoeur reconhece que o pensamento filosófico e teológico ocidental trabalha o tema do mal como totalidade, procura responder à questão: de onde vem o mal ? ${ }^{9}$. E oferece-nos uma episteme sobre o mesmo. Tanto em Santo Agostinho como em Leibniz, teríamos uma ciência que explica o mal.

Já com relação ao sofrimento - nosso maior interesse aqui -, não há uma ciência a respeito. $\mathrm{O}$ mal que o corresponde pode ser observado por analogia a diferentes tipos de atuação, que, no contexto da pandemia do coronavírus no Brasil durante o primeiro semestre de 2020, envolve agentes de governo. Nossa estratégia será visualizar três espécies do mal: a primeira, como atualização mítica da prática do poder que visa ao desamparo na morte; a segunda, o mal como sofrimento intencional resultante da indiferença em face da morte; a terceira, o mal como agência e técnica de governo: o desaparecimento da morte.

\section{Atualização mítica do mal como desamparo diante da morte}

A face mítica do mal, diz Ricoeur, incorpora a experiência fragmentária dos grandes "relatos de origem de alcance cósmico, nos quais a antropogênesis passa a ser uma parte da cosmogênesis" $"$. Mircea Eliade é dos que se interessam pela descrição mítica da gênese humana segundo a perspectiva religiosa, no interior da qual a grandiosidade do sagrado envolve inclusive a explicação acerca do mal: "O mito, quando diz como o mundo começou, diz como a condição humana foi engendrada na sua forma globalmente miserável"11. Mas são as grandes religiões, diz Ricoeur, que se empenham pela explicação global. Entendamos por global, em termos filosóficos, a compreensão da particularidade em relação à universalidade, a contingência e sua relação com a necessidade e, em termos teológicos, a criatura em relação ao criador, o bem em face do mal. Ainda no âmbito mítico, as literaturas do Oriente Antigo, Índia e Extremo Oriente constituem para esse autor um imenso "laboratório de experimentação", segundo o qual

Não há solução imaginável que não tenha sido tentada quanto a toda a ordem de coisas e, portanto, quanto ao enigma do mal. Para lidar com esta variedade infinita, a história comparativa das religiões e a antropologia cultural estabelecem tipologias que dividem as explicações míticas em monismo, dualismo, soluções mistas, etc. ${ }^{12}$.

\footnotetext{
RICOEUR, 2007, p. 35.

9 RICOEUR, 2007, p. 36.

${ }^{10}$ RICOEUR, 2007, p. 28.

${ }^{11}$ RICOEUR, 2007, p. 28.

12 RICOEUR, 2007, p. 30.
} 
Ao recorrer à imaginação mítica, tal "laboratório experimental" não intentava decifrar as entranhas do real. A explicação poderia tão somente jogar luz sobre um enigma, tentar situar a experiência concreta no contexto de uma história pela qual tais povos criadores dos mitos pudessem observar sua própria experiência do cotidiano. $\mathrm{O}$ apelo ao relato não serviria ao julgamento do presente pelo recurso à memória, a partir da comparação com o passado. Tratava-se no caso de atualizar a compreensão da experiência presente em face daquela composição mítica. Tomemos como exemplo uma das tragédias mais comentadas de Sófocles:

Antígona - Comum no sangue, querida irmã, caríssima Ismene, sabes de algum mal, dos que nos vêm de Édipo, que Zeus não queira consumar em nossas vidas? Nada angústia, infortúnio, humilhação, desonra -, não há mal que eu não veja cair sobre ti, sobre mim. E agora... Que novo decreto - propalam - é este que o general acaba de proclamar em toda a cidade? O que sabes? Ouviste algo? Ou ignoras que atacam a entes queridos nossos - malefícios vindos de inimigos? ${ }^{13}$.

Na estrofe de abertura da tragédia, Antígona pergunta à sua irmã Ismene por algum mal que Zeus teria lançado contra seus familiares como punição pelos males anteriores praticados por Édipo, seu pai. Nenhum lhes havia sido enviado como aqueles já corriqueiros, vividos pelos personagens de outras tragédias, a saber: "angústia, infortúnio, humilhação ou desonra" ${ }^{14}$. Nem mesmo aqueles malefícios provenientes dos inimigos Antígona e seus irmãos teriam recebido: ódio, fúria, guerras. O mal pelo qual sofrerão com desespero e fúria resultará de um decreto proclamado a toda a cidade. Tal como se perguntou Ricoeur: quem teria praticado o mal?

Como é bem sabido, o decreto do tirano Creonte dava tratamento diferente aos irmãos de Antígona, mortos em batalha: o primeiro receberia honras e glória; ao segundo seria atribuída a infâmia. Etéocles seria enterrado, tal como o previsto no direito e na lei, sendo-lhe dada uma sepultura digna. Polinice, morto na penúria, deveria ser posto em completo desamparo: ninguém poderia guardá-lo em qualquer cova, nem chorar por sua morte, seria abandonado "sem lágrimas, sem exéquias, doce tesouro de aves, que o espreitam famintas"15. O poder, segundo as ordens de Creonte, instaura a punição aos que se insurgirem contra o desamparo e o abandono de Polinice: "Se alguém transgredir o decreto, receberá a sentença de apedrejamento dentro da cidade" $"$. Antígona encontra-se diante do dilema: resignar-se diante do mal e aceitar o decreto tirânico; não aceitar a condição do desamparo imposta ao irmão e render-lhe as homenagens devidas. Ante as ponderações de Ismene a respeito da ira do tirano, ela não reluta: "Quanto a mim, sepultura vou dar a meu queridíssimo irmão"17.

\footnotetext{
13 SÓFOCLES. Antígona. Trad. Donaldo Schüller. Porto Alegre: L\&PM, 1999. p. 7-8.

14 SÓFOCLES, 1999 , p. 7.

15 SÓFOCLES, 1999, p. 8.

16 SÓFOCLES, 1999, p. 9.

17 SÓFOCLES, 1999, p. 12.
} 
Diferentemente dos intérpretes que se concentram no debate sobre as dimensões da posição humanitária de Antígona, convém recordar que nosso interesse aqui se concentra no mal. A tragédia nos coloca diante das respostas buscadas por Ricoeur acima. Creonte é o autor do ato maléfico. Largar o morto em desamparo completo é o mal inadmissível a Antígona. Ao decretar o desamparo como condenação a Polinice, o tirano age intencionalmente para instaurar o sofrimento não mais àquele que morre - situação diante da qual ele se apresenta indiferente -, mas aos que vivem sem poder chorar, velar, despedir-se daquele posto em desamparo.

A tragédia grega como laboratório experimental poético-mítico buscou imitar as situações mais extremas vividas por homens, mulheres, jovens e crianças daquele povo. A morte e as circunstâncias que a causaram são alguns de seus temas recorrentes. A estratégia de estabelecermos o paralelo face ao presente atualiza nosso entendimento acerca do desamparo em relação à morte. Sendo mais explícito: a reação de alguns governantes brasileiros diante da população na pandemia do novo coronavírus é a fiel expressão do abandono em relação aos mortos e àqueles que por eles sofrem. Tome-se a declaração do presidente da República na entrevista concedida em frente ao Palácio da Alvorada em 27 de abril de 2020: "E daí? Lamento. Quer que eu faça o quê? Eu sou Messias, mas não faço milagre" ${ }^{18}$. Respondeu assim a autoridade máxima do país à indagação sobre o fato de o país ter ultrapassado a China em número de mortes pelo novo coronavírus. Àquela altura da pandemia o Brasil somava algo como 73 mil casos confirmados oficialmente e 5.083 óbitos. O lamento manifestado parece não ter qualquer relação com as vítimas fatais. Na sequência, como se a pandemia não fosse um problema de natureza pública, a mesma autoridade completa: "Eu tenho que falar com o ministro, ele que fala de número. Eu não falo sobre a questão da saúde. Talvez eu leve na quinta-feira para fazer uma live aqui" "19. Coloque-se a devida ênfase na preocupação em relação à live pelas redes sociais, como não vislumbrar que as vítimas estejam em completo desamparo se o chefe político maior do país se exime de falar sobre a questão da saúde em plena pandemia? Apenas após ser avisado que a imprensa gravava as declarações, manifestou: "Lamento a situação que nós atravessamos com o vírus. Nos solidarizamos com as famílias que perderam seus entes queridos, que a grande parte eram pessoas idosas, mas é a vida" ${ }^{20}$.

Ao partilhar o lamento e a solidariedade, somos inclinados a pensar que a autoridade pública não atualiza a posição de Creonte diante do cidadão morto. Mas como explicar que os cidadãos brasileiros não estejam lançados ao abandono político se, ante todos os avisos de autoridades sanitárias mundo afora, tais autoridades tenham classificado a doença como: gripezinha, resfriadinho? Semanas após a primeira morte por Covid-19, oficialmente declarada, Jair Bolsonaro manifesta seu descontentamen-

${ }^{18}$ CHAIB, Julia; CARVALHO, Daniel. “E daí? Lamento, quer que eu faça o quê?”, diz Bolsonaro sobre recorde de mortos por coronavírus. Folha de S. Paulo, São Paulo, 28 de abril de 2020. Disponível em: $<$ https://www1.folha.uol.com.br/equilibrioesaude/2020/04/e-dai-lamento-quer-que-eu-faca-o-que-dizbolsonaro-sobre-recorde-de-mortos-por-coronavirus.shtml>. Acesso em: 11 jul. 2020.

19 CHAIB; CARVALHO, 2020.

${ }^{20}$ CHAIB; CARVALHO, 2020. 
to em relação à imprensa: [os meios de comunicação] “[...] espalharam a sensação de pavor, tendo como carro-chefe o grande número de vítimas na Itália" 21 . Por que os cidadãos não se assustariam diante da morte? Ao reivindicar que "a vida precisa continuar" e "precisamos voltar à normalidade", o presidente da República produziu o atestado confirmando seu desapreço e descompromisso com a situação vivida pela população naquele momento. Em 28 de março de 2020, a pandemia já havia se tornado um problema crítico de saúde pública para mais de 50 países, uma tragédia sob o aspecto das perdas de vidas para: Itália, Espanha e França. Qual seria a reação normal do cidadão comum nessa situação: temer pela morte ou ignorar que a ameaça à vida estava diante de todos? Onde mais se poderia localizar a prática do mal a não ser nas atitudes de descaso, abandono e negação das mortes por parte de autoridades responsáveis?

Do ponto de vista da autoridade mencionada, o esforço para manifestar a negação da gravidade do problema tornou-se inversamente proporcional ao avanço do número de mortos no país. ${ }^{22}$ Em 16 de março de 2020, a principal autoridade pública do Brasil afirmou: "Crise do coronavírus "não é isso tudo que dizem"" 23 . Nenhum recuo com admissão da gravidade do problema, as raras manifestações de preocupação das autoridades governamentais com a saúde da população foram, de fato, convincentes. Em um dia, o presidente da República pede a quem tem fé que faça jejum "para todo o povo brasileiro, em nome, obviamente, de que o Brasil fique livre desse mal o mais rápido possível" 24 ; poucos dias antes afirmara: "Brasileiro não pega nada, o cara pula no esgoto e não fica doente" 25 .

Os apelos de autoridades, como o presidente da República, para normalizar a situação - defesa da abertura das escolas, citação de que empregos estavam ameaçados em razão da "histeria da mídia" sobre a doença e as mortes, oferta de medicamento sem eficácia científica comprovada no tratamento - adensam a percepção de que a

${ }^{21}$ COLETTA, Ricardo Della. Em pronunciamento, Bolsonaro critica fechamento de escolas, ataca governadores e culpa mídia. Folha de S. Paulo, São Paulo, 24 de março de 2020. Disponível em: <https:// www1.folha.uol.com.br/poder/2020/03/em-pronunciamento-bolsonaro-critica-fechamento-de-escolasataca-governadores-e-culpa-midia.shtml>. Acesso em: 11 jul. 2020.

22 Em 26 de fevereiro de 2020 foi notificado o primeiro caso no Brasil. Cinco meses após, a pandemia já atinge 196 países em todos os continentes, segundo a Organização Mundial da Saúde (OMS), e registra 611.599 mortes até 21 de julho. Em 25 de julho de 2020, o país já contava mais de 85 mil mortos e tanto os especialistas calculavam quanto os meios de comunicação noticiavam a chegada a 100 mil vítimas fatais para antes da metade do mês de agosto de 2020.

${ }^{23}$ URIBE, Gustavo. Mesmo após 6.513 mortes, Bolsonaro diz que crise do coronavírus "não é isso tudo que dizem”. Folha de São Paulo, São Paulo, 16 de março de 2020. Disponível em: <https://www1.folha. uol.com.br/poder/2020/03/mesmo-apos-6513-mortes-bolsonaro-diz-que-crise-do-coronavirus-nao-e-issotudo-que-dizem.shtml>. Acesso em: 13 jul. 2020.

24 SOARES, Ingrid. Bolsonaro quer um dia de jejum religioso contra coronavírus. Correio Braziliense, Brasília, 02 de abril de 2020. Disponível em: < https://www.correiobraziliense.com.br/app/noticia/ politica/2020/04/02/interna_politica,842034/bolsonaro-quer-um-dia-de-jejum-religioso-contracoronavirus.shtml>. Acesso em: 19 jul. 2020.

25 MARAKAWA, Fabio. Bolsonaro: brasileiro não pega nada, o cara pula no esgoto e não fica doente. Valor Investe, Brasília, 23 de março de 2020. Disponível em: $<$ https://valorinveste.globo.com/mercados/brasil-epolitica/noticia/2020/03/26/bolsonaro-brasileiro-nao-pega-nada-o-cara-pula-no-esgoto-e-nao-fica-doente. ghtml>. Acesso em: 15 jul. 2020. 
morte em escalada vale pouco ou quase nada. Não se trata de responsabilizar quem quer que seja pela origem ou a existência da doença, pelo seu contágio rápido e abrangente. Mas negar que uma ameaça rodeava os cidadãos corresponde ao que Antígona identifica como o mal atribuído a Polinice, abandonado e entregue às aves de rapina.

\section{O mal padecido: difusão intencional do sofrimento pelo poder político}

O desprezo de autoridades públicas ante a morte de cidadãos não exprime o mal apenas pela postura da indiferença. A tragédia mesma nos informa que o abandono à morte resulta de um ato intencional para gerar sofrimento. Nesse caso, não se tratava apenas de repreender o morto por sua conduta, suposta traição. A intenção de Creonte era também a de gerar o sofrimento aos vivos - às irmãs Antígona e Ismene. É bem verdade que no contexto das criações mítico-poéticas a experiência do sofrimento como expressão do mal se apresenta em meio a comportamentos ambíguos, atitudes paradoxais, cálculos perversos e maquinações pérfidas de personagens que tornam complexo o julgamento por parte do leitor e da leitora. No entanto, como a intenção é instigar a condenação ética e moral, a localização do mal corresponde quase sempre aos atos intencionais que causam o sofrimento alheio.

Essa atuação intencional em favor do sofrimento põe ênfase no que Ricoeur chama de o mal que nos afeta. ${ }^{26}$ Seja ele proveniente de uma adversidade de natureza física, incapacidade do corpo e/ou da mente, seja ele a "perspectiva aterradora da própria mortalidade [...] o sofrimento está relacionado à diminuição de nossa integridade física, psíquica ou espiritual' ${ }^{27}$. Diferentemente do desvio moral, cujo mal é identificado em decorrência de uma avaliação do agente e do reconhecimento própria da falha quando da manifestação da culpa, o mal que instila o sofrimento intenciona a subtração de alguma potencialidade alheia, o esvaziamento da força "física, psíquica e espiritual" daquele a quem o ato se dirige. No caso da condenação estabelecida por Creonte, a intenção de infundir o sofrimento visava atingir os parentes de Polinice, assim como os cidadãos que o conheciam, os habitantes de Tebas.

Não é por outro motivo que Ricoeur explica-nos que o sofrimento como um mal "opõe-se à reprovação e ao lamento" 28 . Quem é Antígona senão a mulher que se levanta em reprovação à determinação do tirano? A indignação que ela manifesta é uma recusa ao sequestro de sua força "física, psíquica e espiritual", ela se insurge contra a intenção do tirano de fragilizar a condição dos cidadãos em face do poder tirânico. Como afirma Ricoeur, o sofrimento faz do outro a quem ele atinge uma vítima. ${ }^{29} \mathrm{O}$ grito de lamento e de recusa da condição de vítima, por sua vez, exprime a rejeição ao mal, ainda que essa manifestação seja insuficiente. Que situação na pandemia enqua-

\footnotetext{
${ }^{26}$ RICOEUR, 2007, p. 24-25.

27 RICOEUR, 2007, p. 24-25.

28 RICOEUR, 2007, p. 24-25.

${ }^{29}$ RICOEUR, 2007, p. 24-25.
} 
draria os cidadãos na condição de vítimas afetadas pelo sofrimento? De onde partiria essa intenção de prática do mal como difusão do sofrimento?

Tomemos como referência do presente aspectos da polêmica acerca dos remédios sem eficácia cientificamente comprovada, mas larga e intencionalmente divulgados por autoridades governamentais brasileiras como opção de tratamento ou cura à Covid-19. Nenhuma dúvida há quanto à intenção e ao empenho de tais autoridades - especificamente o presidente da República e o ocupante interino do Ministério da Saúde, desde 16 de maio de 2020 - para difundir o uso de tais medicamentos. O próprio Ministério da Saúde chegou a desenvolver um protocolo e divulgou as orientações para ampliar o acesso de pacientes com Covid-19 ao tratamento precoce, ou seja, nos primeiros dias de sintomas, no âmbito do Sistema Único de Saúde (SUS). O site do SUS anunciou, em 20 de maio de 2020, "a orientação para prescrição a pacientes adultos de dois medicamentos associados à azitromicina: a cloroquina e o sulfato de hidroxicloroquina" "30. A Associação Médica Brasileira (AMB), em 21 de maio de 2020, alertou sobre a falta de medicamentos comprovadamente eficazes, mas reiterou "a excepcionalidade do uso da cloroquina e da hidroxicloroquina no cenário da pandemia" 31 . Nesse momento alegava não haver então pesquisas aprofundadas e conclusivas sobre os benefícios ou a segurança do medicamento nas diversas fases da doença Covid-19. Manteve o apoio à indicação desse medicamento pelos médicos, mesmo após a constatação da sua ineficácia pela Organização Mundial da Saúde (OMS) e da desistência por essa entidade dos estudos para tratamento dessa doença com tal medicação. ${ }^{32}$ Ressaltem-se nesse mesmo período os contundentes avisos e estudos $^{33}$ de associações de infectologistas, entre outros, sobre a necessidade do aban-

30 MINISTÉRIO DASAÚDE. Ministério da Saúde divulga diretrizes para tratamento medicamentoso de pacientes. 20 de maio de 2020. Disponível em: $<$ https://www.saude.gov.br/noticias/agencia-saude/46919-ministerio-dasaude-divulga-diretrizes-para-tratamento-medicamentoso-de-pacientes $>$. Acesso em: 16 jul. 2020.

31 ASSOCIAÇÃO MÉDICA BRASILEIRA. Nota AMB sobre tratamento precoce de Covid-19 com uso de Cloroquina e Hidroxicloroquina. 21 de maio de 2020. Disponível em: <https://amb.org.br/noticias/ $\mathrm{amb} /$ nota-amb-sobre-tratamento-precoce-de-covid-19-com-uso-de-cloroquina-e-hidroxicloroquina/>. Acesso em: 16 jul. 2020. Mesmo após estudos confirmando a ineficácia do produto, a mesma associação enfatiza, em nota de 19 de julho de 2020, que não há estudos conclusivos a respeito e defende a autonomia dos médicos no uso dessa solução medicamentosa. Disponível em: <https:/amb.org.br/noticias/ hidroxicloroquina-amb-defende-autonomia-do-medico/>. Acesso em: 20 jul. 2020.

32 TREZZINA, Martial. OMS encerra em definitivo estudo com hidroxicloroquina para tratamento da covid. Valor Econômico, São Paulo, 04 de julho de 2020. Disponível em: <https://valor.globo.com/mundo/ noticia/2020/07/04/oms-paralisa-testes-com-lopinavir-e-ritonavir-no-tratamento-de-coronavrus.ghtml >. Acesso em: 18 jul. 2020.

33 MARTINS, Elisa. Estudo brasileiro mostra ineficácia de hidroxicloroquina e azitromicina em casos leves a moderados de Covid-19. O Globo, Rio de Janeiro, 23 de julho de 2020. Disponível em: $<$ https:// oglobo.globo.com/sociedade/coronavirus/estudo-brasileiro-mostra-ineficacia-de-hidroxicloroquinaazitromicina-em-casos-leves-moderados-de-covid-19-24547361?utm_source=notificacao-geral\&utm medium $=$ notificacao-browser\&utm_campaign $=\mathrm{O} \% 20 \mathrm{Globo}>$. Acesso em: 23 jul. 2020. Destaque-se que a pesquisa teve a participação de 55 hospitais públicos e privados de ponta do Brasil, e os resultados foram publicados em 23/07/2020 no prestigiado periódico científico New England Journal of Medicine. 
dono dessa solução. ${ }^{34}$ Autoridades médicas reafirmaram seguidamente mundo afora que, não obstante sejam impotentes com relação ao vírus, tais substâncias podem induzir efeitos colaterais e, em casos extremos, chegam a causar a morte. Como assinalou a $\mathrm{AMB}^{35}$, não há o que se discutir sobre a autonomia da decisão médica acerca do necessário para o restabelecimento da saúde de quem quer que seja. Por outro lado, o conflito entre posições dos especialistas em saúde certamente ensejará debates sobre os limites éticos da atuação profissional em situações extremas, como na pandemia da Covid-19. Mas o que dizer sobre os procedimentos de autoridades políticas, como o presidente da República e seu subordinado ministro da Saúde? É possível reduzir tal orientação ao mero desvio ético e moral? Por que autoridades governamentais - sem conhecimento médico - insistiram e insistem em publicar um procedimento que pode resultar em comprometimento da saúde dos cidadãos?

A intenção de promover e indicar tais medicamentos por desconhecedores da medicina envolve a exposição da população ao risco de fragilização da saúde, até à morte. Não seria tal interesse compatível com um ato que adiciona o sofrimento ao medo das vítimas diante da doença imprevisível? Ricoeur adverte que, do ponto de vista teológico cristão, a raiz comum do pecado e do sofrimento explica a vinculação de ambos ao ato maléfico. ${ }^{36}$ A diferença entre um e outro é que o segundo se associa indelevelmente à produção intencional do sofrimento. No caso dos brasileiros afetados pela Covid-19, os agentes públicos engajados nessa produção da falsa sensação de segurança e cura contribuem diretamente para a fratura - palavras de Ricoeur - entre o mal cometido e o mal padecido. ${ }^{37}$ E completa:

Uma causa principal do sofrimento é a violência exercida pelo homem sobre o homem: na verdade, fazer o mal é sempre prejudicar outro direta ou indiretamente e, consequentemente, fazê-lo sofrer; na sua estrutura relacional - dialógica -, o mal cometido por um encontra a sua resposta no mal sofrido pelo outro ${ }^{38}$.

É uma violência, portanto, o estímulo intencional por autoridades do Estado brasileiro ao uso de medicação que, sem qualquer eficácia cientificamente comprovada, põe a saúde da população em risco. O fato de que dezenas de milhares de cidadãos mortos não seja fator suficiente para demover agentes públicos de ações que criam falsa expectativa de cura e ilusão de proteção não deixa dúvidas sobre a intencionalidade dos atos. $\mathrm{O}$ fato decisivo que denuncia o comprometimento dessa

34 ESTADÃO. Sociedade de Infectologia orienta que hidroxicloroquina seja abandonada no tratamento da covid-19. São Paulo, O Estado de São Paulo, 17 de julho de 2020. Disponível em: <https: //saude. estadao.com.br/noticias/geral,estudos-comprovam-que-hidroxicloroquina-e-ineficaz-contra-covid-19-dizsociedade-de-infectologia,70003367683>. Acesso em: 20 jul. 2020.

35 ASSOCIAÇÃO MÉDICA BRASILEIRA. Hidroxicloroquina: AMB defende autonomia do médico. 19 de julho de 2020. Disponível em: <https://amb.org.br/noticias/hidroxicloroquina-amb-defende-autonomiado-medico/>. Acesso em: 20 jul. 2020.

${ }^{36}$ RICOEUR, 2007, p. 24.

37 RICOEUR, 2007, p. 25.

38 RICOEUR, 2007, p. 25. 
intencionalidade com o mal, tal como estabelecido por Ricoeur: "prejudicar outro direta ou indiretamente e, consequentemente, fazê-lo sofrer", é a publicação do conteúdo da ata da reunião do Comitê de Operações de Emergência em Saúde Pública, ocorrida em 25 de maio de 2020. A autoridade de Saúde do país então, Eduardo Pazuello, ministro interino da Saúde, foi alertado sobre os benefícios do isolamento social para reduzir o impacto da pandemia. O Ministério adotou orientação contrária, mesmo tendo sido alertado que sem as medidas de isolamento severo o país conviverá com os efeitos da pandemia por até dois anos. Em portaria publicada pelo ministério, em 19 de junho de 2020, lê-se:

[...] retomar as atividades e o convívio social são também fatores de promoção da saúde mental das pessoas, uma vez que o confinamento, o medo do adoecimento e da perda de pessoas próximas, a incerteza sobre o futuro, o desemprego e a diminuição da renda, são efeitos colaterais da pandemia pelo sars-cov-2 e têm produzido adoecimento mental em todo o mundo ${ }^{39}$.

A tradição teológica desde Agostinho nos ensina que estão associados ao mal o pecado, o sofrimento e a morte. O sofrimento e a morte no contexto em que ocorre a pandemia de Covid-19, no Brasil, constituem especificamente o mal padecido. Afora o acaso da ocorrência de uma peste, como afirma o epidemiologista Roberto Medronho: o problema mais grave dos últimos 100 anos na saúde do país, provocando crise humanitária, no Brasil e no mundo"40, uma série de decisões governamentais prejudicam e atingem parte da população.

\section{Intenção, plano e ataque sistemático: desaparecimento da morte e estratégia de governo}

A jurista Deisy Ventura, especialista na relação entre pandemias e direito, defende que a resposta do governo brasileiro à Covid-19 tem todos os elementos necessários para a tipificação de crimes contra a humanidade. ${ }^{41}$ Acrescenta que "o crime de

39 G1. Comitê alertou Pazuello que, sem isolamento, país poderia levar até 2 anos para controlar a pandemia. 23 de julho de 2020. Disponível em: <https://g1.globo.com/politica/noticia/2020/07/23/comite-doministerio-alertou-pazuello-que-sem-isolamento-pais-poderia-levar-ate-2-anos-para-controlar-a-pandemia. ghtml>. Acesso em: 23 jul. 2020.

40 E completa: "Nós precisamos de que a direção central desse processo seja do Ministério da Saúde, e que seja, mais do que nunca, sejam ouvidas as pessoas que realmente tenham experiência para o controle e o combate da pandemia de Covid-19” [...] “Ainda há tempo, podemos reduzir o número de mortes e de sofrimento, mas eu faço aqui um apelo para que estejamos todos unidos contra este vírus. Foi assim que mundo inteiro agiu e foi assim que em muitos lugares o êxito foi muito importante para o enfrentamento desse grave problema". Cf. G1. Comitê alertou Pazuello que, sem isolamento, país poderia levar até 2 anos para controlar a pandemia. 23 de julho de 2020. Disponível em: <https://g1.globo.com/politica/ noticia/2020/07/23/comite-do-ministerio-alertou-pazuello-que-sem-isolamento-pais-poderia-levar-ate2-anos-para-controlar-a-pandemia.ghtml>. Acesso em: 23 jul. 2020.

41 BRUN, Eliane. Há indícios significativos para que autoridades brasileiras, entre elas o presidente, sejam investigadas por genocídio. EL PAÍS, 22 de julho de 2020. Disponível em: < https://brasil.elpais.com/ 
extermínio é a sujeição intencional a condições de vida que podem causar a destruição de uma parte da população" ${ }^{2}$. Com relação às populações indígenas, a estudiosa não tem dúvidas de que seja o caso. O mesmo também se pode dizer a respeito das populações mais atingidas pela doença: pretos, populações periféricas nas grandes cidades - como São Paulo - e os idosos.

O debate filosófico-jurídico centra-se na noção de intencionalidade, vertente que segue trilha parecida com a de Ricoeur acima. Ventura sustenta não haver dúvidas de que atos e discursos governamentais a respeito disseminam falsas informações, assim como no caso dos indígenas houve "um conjunto de ações, inclusive por via legislativa, para obstaculizar as medidas de combate e prevenção à Covid-19 de iniciativa de outros poderes" ${ }^{\prime 4}$. A pesquisadora avança inclusive para defender a tipificação de genocídio no caso dos indígenas. Mais cético em relação ao emprego do termo genocídio, o advogado Luís Moreno Ocampo - primeiro promotor-chefe do Tribunal Penal Internacional (TPI) em Haia, Holanda -, afirma que para uma condenação é preciso provar que houve um plano de usar o coronavírus "como ferramenta para exterminar toda ou parte da população" "44. A intenção de burlar regras e difundir posições negacionistas efetuada por autoridades governamentais brasileiras talvez não configure crime suficiente, pondera Ocampo, para uma condenação judicial no TPI por mortandades em larga escala. Genocídio ou não, passíveis de condenação internacional ou não, o debate entre juristas acerca dos posicionamentos discursivos e ações de governantes brasileiros em relação à pandemia de Covid-19 promete ser tão intenso e inovador quanto o dos médicos.

Retomando o fio do estudo de Ricoeur, lembre-se que a seu ver o mal não é redutível a um exercício especulativo, ou mesmo à introspecção que mira a indagação de ações individuais e o posterior reconhecimento do erro com a manifestação do sentimento de culpa. O mal é também uma forma de ação individual que envolve e intencionalmente prejudica o outro indivíduo. Como tal, diz o pensador, tem que ser combatido. ${ }^{45}$ Segundo Ricoeur, a localização do mal na ação intencional inverte nossa percepção ou perspectiva de observação do tema. Esse tipo de ação reiterada, que inclusive se atualiza, nos coloca diante de uma realidade do mal que se distancia inclusive daquela que observamos no mito.

A reiteração do ato mau põe ênfase no fato de que a intenção se ausenta da admissão de qualquer culpa ou arrependimento. Quanto a esse aspecto, as autoridades governamentais brasileiras - especificamente o presidente da República e o ministro interino da Saúde, no período da Covid-19 - poderiam se defender dizendo que a

brasil/2020-07-22/ha-indicios-significativos-para-que-autoridades-brasileiras-entre-elas-o-presidente-sejaminvestigadas-por-genocidio.html\#?sma=newsletter_brasil_diaria20200723>. Acesso em: 23 jul. 2020.

42 BRUN, 2020.

${ }^{43}$ BRUN, 2020.

${ }^{44}$ HAIDAR, Daniel. Para que Bolsonaro seja julgado em Haia é preciso mostrar a intenção de crime contra a humanidade. EL PAÍS, 22 de julho de 2020. Disponível em: <https://brasil.elpais.com/brasil/2020-07-21/ para-que-bolsonaro-seja-julgado-em-haia-e-preciso-mostrar-a-intencao-de-crime-contra-a-humanidade. html>. Acesso em: 24 jul. 2020.

${ }^{45}$ RICOEUR, 2007, p. 60. 
pandemia é um evento episódico, razão pela qual equívocos de atuação estariam previstos. Mas observe-se a polêmica sobre o caso da contagem do número de mortos. Desde o início de junho de 2020, veículos de imprensa noticiaram a inconsistência dos dados apresentados pela instituição governamental responsável. Em um intervalo de poucas horas, no dia 07 de julho, o Ministério da Saúde divulgou dados divergentes sobre o número de mortos e de contaminados. O fato repercutiu mundo afora após se constatar que a ordem para a interrupção da publicação dos números partiu de ninguém menos que o presidente da República. O espanto no país foi ecoado por autoridades governamentais dos estados. "A tentativa autoritária, insensível, desumana e antiética de tornar invisíveis os mortos por Covid-19 não terá êxito. Nós e a sociedade brasileira não os esqueceremos, nem a tragédia que se abate sobre a nação" ${ }^{46}$, disse Alberto Beltrame, presidente do Conselho Nacional dos Secretários de Estado da Saúde do Brasil. Havia pelo menos três dias que os dados sobre mortos e contaminados eram díspares entre o número proveniente dos estados da federação e aqueles divulgados, ou não, pelos órgãos federais.

Esconder os mortos, desaparecer com a morte por decisão governamental. Um dos ministros do Supremo Tribunal Federal (STF), Gilmar Mendes, em mensagem nas redes sociais, foi taxativo: "A manipulação das estatísticas é uma manobra de regimes totalitários". Rodrigo Maia, presidente da Câmara Federal dos Deputados, declarou: "O truque não isentará a responsabilidade pelo eventual genocídio", é preciso "transparência" nos dados. ${ }^{47}$ Tentando amenizar as críticas, autoridades governamentais responderam que se tratava de erros na quantificação dos dados provenientes de diferentes localidades do país. ${ }^{48}$ Contudo, ninguém - presidente da República ou ministro da Saúde - negou que a intenção do governo fosse a de desaparecer com os mortos e tirar a atenção da população sobre a gravidade da situação. A intenção de sonegar dados envolve o desparecimento, assim como torna mais dramática a situação da subnotificação a respeito da Covid-19. ${ }^{49} \mathrm{O}$ caso é apenas uma mostra a mais da calamidade pública a que se chega no país em razão de atitudes das autoridades governamentais. Em face do conhecimento das autoridades de saúde internacionais, é uma afronta aos princípios básicos do humanitarismo difundido pela Organização as Nações Unidas (ONU) desde a publicação da Declaração Universal dos Direitos Humanos, em 1948.

46 PHILLIPS, Dom. Brazil stops releasing Covid-19 death toll and wipes data from official site. The Guardian, Rio de Janeiro, 07 de junho de 2020. Disponível em: <https://www.theguardian.com/world/2020/jun/07/ brazil-stops-releasing-covid-19-death-toll-and-wipes-data-from-official-site>. Acesso em: 01 jul. 2020. Tradução nossa.

47 PHILLIPS, 2020.

48 MACHADO, Renato. Após ameaçar sonegar dados, governo promove confusão com números da Covid-19. Folha de São Paulo, 07 de junho de 2020. Disponível em: <https:/www1.folha.uol.com.br/ cotidiano/2020/06/apos-ameacar-sonegar-dados-governo-promove-confusao-com-numeros-a-covid-19. shtml>. Acesso em: 22 jul. 2020.

49 LOPES, Natan. Mortes por síndrome respiratória no Brasil aumentam 20 vezes na pandemia. UOL, 04 de junho de 2020. Disponível em: <https://noticias.uol.com.br/saude/ultimas-noticias/redacao/2020/06/04/ obitos-srag-brasil-coronavirus.htm>. Acesso em: 20 jul. 2020. 
A discussão acerca do genocídio, como aventamos acima, se abrirá para um outro conjunto de temas conexos e detalhes conceituais. Mas é revelador o fato de que os militares estejam associados a esse desprezo humanitário e ao desparecimento dos mortos pela Covid-19. Como afirma Ricoeur, "a violência nunca deixa de recompor a unidade entre o mal moral e o sofrimento" ${ }^{50}$. A recomposição da violência, ou sua atualização como dissemos acima, reconecta os atos militares na saúde durante a pandemia com o passado brasileiro. A tentativa de normalização da tragédia humanitária e a redução do desaparecimento dos mortos a um mero problema de quantificação de dados manteria atualizada em certo sentido a violência como técnica de governo já visto durante a ditadura de 1964-1984. A tentativa de manipulação dos dados durante a pandemia da Covid-19 é uma entre outras estratégias operacionais que visam ao abrandamento da indignação dos cidadãos. Estariam os militares no poder atual atualizando o obscurantismo acerca das mortes e dos mortos como modus operandi governamental já aplicado em passado próximo ${ }^{51}$ Se se trata aqui de uma operatividade intencional, uma estratégia de governo, uma técnica de gestão do Estado, é preciso dizer como Ricoeur: a das realidades do mal se expressa nesse compromisso em infundir o sofrimento e a dor ao outro.

\section{Considerações finais: três breves observações acerca da reação contra o mal}

Ao investigar detalhes da métrica do poema grego, Aristóteles nos ensinou que a tragédia é a "representação de uma ação grave, [...] a qual inspirando pena e temor, opera a catarse própria dessas emoções" 52 . Entre os gregos, a representação mítica da violência e do mal visava à purgação ética. A intenção de transformar os hábitos e os costumes pela visualização dos horrores que nós humanos, os cidadãos, cometemos. Nas tragédias, assim como nas narrativas mitológicas, a presença do mal é uma constante. A denúncia contra a violação das vidas como um mal incontornável é um recurso valioso para a formação ética dos cidadãos.

A materialidade do mal é inquestionável: ela se compõe da violação à vida e do sofrimento praticado ao outro. Tal como argumenta Butler:

Afirmar que uma vida pode ser lesada, por exemplo, ou que pode ser perdida, destruída ou sistematicamente negligenciada até a morte é sublinhar não somente a finitude de

${ }^{50}$ RICOEUR, 2007, p. 60.

51 O antropólogo Piero Leirner analisa, sob vários aspectos, motivos que levaram os militares brasileiros a retomar, desde 2014, a condução e o controle de processos políticos e instituições do Estado. Segundo essa análise, não há qualquer dúvida acerca das intenções e da operatividade governamentais em sintonia com critérios e interesses de autoridades militares, algumas inclusive remanescentes dos ocupantes do poder político na ditadura 1964-1984. Cf. FERRAZ, Ricardo. Bolsonaro tem papel de "causar explosão" para permitir ação "reparadora” de militares, diz antropólogo. BBC News Brasil, São Paulo, 07 de junho de 2020. Disponível em: <https://www.bbc.com/portuguese/brasil-52926714>. Acesso em: 23 jul. 2020.

52 ARISTÓTELES. Arte Poética. Trad. Jaime Bruna. São Paulo: Cultrix, 1997. p. 24. (A poética clássica). 
uma vida (o fato de que a morte é certa), mas também sua precariedade (porque a vida requer que várias condições sociais e econômicas sejam atendidas para ser mantida como uma vida). A precariedade implica viver socialmente, isto é, o fato de que a vida de alguém está sempre, de alguma forma, nas mãos do outro. Isso implica estarmos expostos não somente àqueles que conhecemos, mas também àqueles que não conhecemos, isto é, dependemos das pessoas que conhecemos, das que conhecemos superficialmente e das que desconhecemos totalmente ${ }^{53}$.

A filósofa destaca como inaceitável e negligente o simples reconhecimento de que a morte é certa. Recordemos as palavras do presidente da República, Jair Bolsonaro: "É o destino de todo mundo" 54 . Respondeu essa autoridade a uma eleitora, que o interpelou por uma palavra de alento aos enlutados pela morte de parentes por coronavírus. Butler não hesitaria em alertar que a repulsa ao pouco caso e ao abandono diante da morte é um ato necessário em face da nossa condição de fragilidade. Uma morte, qualquer morte humana, é um evento que denota a nossa precariedade e, como tal, exige a proteção e o acolhimento, destaque-se, mesmo daqueles que "conhecemos superficialmente e das [pessoas] que desconhecemos totalmente" ${ }^{55}$. O poeta metafísico inglês John Donne (1572-1631) escreveu Devoções para Ocasiões Emergentes (1624) tendo essa verdade em mente, em particular, no trecho notável da Meditação XVII, em tradução de Paulo Viziolii ${ }^{56}$.

Nenhum homem é uma ilha, completa em si mesma; todo homem é um pedaço do continente, uma parte da terra firme. Se um torrão de terra for levado pelo mar, a Europa fica menor, como se tivesse perdido um promontório, ou perdido o solar de um teu amigo, ou o teu próprio. A morte de qualquer homem diminui a mim, porque na humanidade me encontro envolvido; por isso, nunca mandes indagar por quem os sinos dobram; eles dobram por ti. [...]

Ricoeur associa a luta contra o mal à possibilidade de diminuição do sofrimento. "Não há necessidade de temer que a ênfase na luta prática contra o mal faça com que o sofrimento seja novamente perdido de vista." ${ }^{57}$ A "luta prática" contra o mal comporta tanto as ações individuais quanto envolve o contexto mais amplo da vida em comum: é uma atuação ética e política.

Seja ética ou política, qualquer ação que diminua a quantidade de violência exercida por alguns homens contra outros diminui o nível de sofrimento no mundo. Se descontássemos

53 BUTLER, Judith. Vida precária, vida passível de luto. In: Quadros de guerra. Rio de Janeiro: Civilização Brasileira, 2018. p. 31.

54 G1. "É o destino de todo mundo", afirma Bolsonaro após lamentar mortes por coronavírus. Disponível em: <https://g1.globo.com/politica/noticia/2020/06/02/e-o-destino-de-todo-mundo-afirma-bolsonaroapos-lamentar-mortes-por-coronavirus.ghtml>. Acesso em: 22 jul. 2020.

55 BUTLER, 2018, p. 31.

56 Disponível em:<https://armazemdetexto.blogspot.com/2017/11/texto-meditacao-xvii-jonh-donne-com.html>.

57 RICOEUR, 2007, p. 60. 
o sofrimento infligido aos homens pelos homens, veríamos o que resta dele no mundo; para dizer a verdade, não sabemos, até que ponto a violência permeia o sofrimento. ${ }^{58}$

Como se complementasse a tradição teológica agostiniana, para a qual o mal se restringe à dimensão ética, Ricoeur acrescenta a atuação contra violência de homens contra homens - uma atuação política - como exemplo de luta prática. É certo que o sofrimento concerne também às catástrofes naturais e às epidemias, até mesmo ao envelhecimento e à morte. Mas a intenção é o que distingue o sofrimento imprevisto daquele que resulta da prática do mal. É contra essa intencionalidade aliada da violência, do desamparo e da negligência que se constitui a luta prática defendida por Ricoeur contra o mal.

\section{Referências}

ARISTÓTELES. Arte Poética. Trad. Jaime Bruna. São Paulo: Cultrix, 1997. (A poética clássica). ASSOCIAÇÃO MÉDICA BRASILEIRA. Nota AMB sobre tratamento precoce de Covid-19 com uso de Cloroquina e Hidroxicloroquina. 21 de maio de 2020. Disponível em: $<$ https://amb. org.br/noticias/amb/nota-amb-sobre-tratamento-precoce-de-covid-19-com-uso-de-cloroquinae-hidroxicloroquina/>. Acesso em: 16 jul. 2020.

. Hidroxicloroquina: AMB defende autonomia do médico. 19 de julho de 2020. Disponível em: $<$ https://amb.org.br/noticias/hidroxicloroquina-amb-defende-autonomia-do-medico/ $>$. Acesso em: 20 jul. 2020.

BRUN, Eliane. Há indícios significativos para que autoridades brasileiras, entre elas o presidente, sejam investigadas por genocídio. EL PAÍS, 22 de julho de 2020. Disponível em: <https:// brasil.elpais.com/brasil/2020-07-22/ha-indicios-significativos-para-que-autoridades-brasileirasentre-elas-o-presidente-sejam-investigadas-por-genocidio.html\#?sma=newsletter_brasil diaria20200723>. Acesso em: 23 jul. 2020.

BUTLER, Judith. Quadros de Guerra: quando a vida é passível de luto? Rio de Janeiro: Civilização Brasileira, 2018.

CHAIB, Julia; CARVALHO, Daniel. “E daí? Lamento, quer que eu faça o quê?”, diz Bolsonaro sobre recorde de mortos por coronavírus. Folha de S. Paulo, São Paulo, 28 de abril de 2020. Disponível em: $<$ https://www1.folha.uol.com.br/equilibrioesaude/2020/04/e-dai-lamento-querque-eu-faca-o-que-diz-bolsonaro-sobre-recorde-de-mortos-por-coronavirus.shtml $>$. Acesso em: 11 jul. 2020.

COLETTA, Ricardo Della. Em pronunciamento, Bolsonaro critica fechamento de escolas, ataca governadores e culpa mídia. Folha de S. Paulo, São Paulo, 24 de março de 2020. Disponível em: <https://www1.folha.uol.com.br/poder/2020/03/em-pronunciamento-bolsonaro-criticafechamento-de-escolas-ataca-governadores-e-culpa-midia.shtml $>$. Acesso em: 11 jul. 2020.

ESTADÃO. Sociedade de Infectologia orienta que hidroxicloroquina seja abandonada no tratamento da covid-19. O Estado de São Paulo, São Paulo, 17 de julho de 2020. Disponível em: $<$ https://saude.estadao.com.br/noticias/geral,estudos-comprovam-que-hidroxicloroquina-eineficaz-contra-covid-19-diz-sociedade-de-infectologia,70003367683>. Acesso em: 20 jul. 2020.

${ }^{58}$ RICOEUR, 2007, p. 60-61. 
FERRAZ, Ricardo. Bolsonaro tem papel de "causar explosão" para permitir ação "reparadora" de militares, diz antropólogo. BBC News Brasil, São Paulo, 07 de junho de 2020. Disponível em: <https://www.bbc.com/portuguese/brasil-52926714>. Acesso em: 23 jul. 2020.

GILSON, Étienne. O Espírito da Filosofia Medieval. São Paulo: Martins Fontes, 2006.

HAIDAR, Daniel. Para que Bolsonaro seja julgado em Haia é preciso mostrar a intenção de crime contra a humanidade. EL PAÍS, 22 de julho de 2020. Disponível em: <https://brasil.elpais. com/brasil/2020-07-21/para-que-bolsonaro-seja-julgado-em-haia-e-preciso-mostrar-a-intencaode-crime-contra-a-humanidade.html>. Acesso em: 24 jul. 2020.

MARAKAWA, Fabio. Bolsonaro: brasileiro não pega nada, o cara pula no esgoto e não fica doente. Valor Investe, Brasília, 23 de março de 2020. Disponível em: <https://valorinveste.globo. $\mathrm{com} / \mathrm{mercados} /$ brasil-e-politica/noticia/2020/03/26/bolsonaro-brasileiro-nao-pega-nada-o-carapula-no-esgoto-e-nao-fica-doente.ghtml>. Acesso em: 15 jul. 2020.

METZ, Johann Baptist. La "memoria passionais" como categoria fundamental de la teologia política. In: Memoria Passionis. Una evocación provocadora em uma sociedade pluralista. Santander: Salterrae, 2007. p. 246-251.

G1. Comitê alertou Pazuello que, sem isolamento, país poderia levar até 2 anos para controlar a pandemia. 23 de julho de 2020. Disponível em: <https://g1.globo.com/politica/noticia/2020/07/23/ comite-do-ministerio-alertou-pazuello-que-sem-isolamento-pais-poderia-levar-ate-2-anos-paracontrolar-a-pandemia.ghtml>. Acesso em: 23 jul. 2020.

LOPES, Natan. Mortes por síndrome respiratória no Brasil aumentam 20 vezes na pandemia. UOL, 04 de junho de 2020. Disponível em: $<$ https://noticias.uol.com.br/saude/ultimas-noticias/ redacao/2020/06/04/obitos-srag-brasil-coronavirus.htm>. Acesso em: 20 jul. 2020.

MACHADO, Renato. Após ameaçar sonegar dados, governo promove confusão com números da Covid-19. Folha de São Paulo, 07 de junho de 2020. Disponível em: <https://www1.folha. uol.com.br/cotidiano/2020/06/apos-ameacar-sonegar-dados-governo-promove-confusao-comnumeros-a-covid-19.shtml>. Acesso em: 22 jul. 2020.

MARTINS, Elisa. Estudo brasileiro mostra ineficácia de hidroxicloroquina e azitromicina em casos leves a moderados de Covid-19. O Globo, Rio de Janeiro, 23 de julho de 2020. Disponível em: <https:/oglobo.globo.com/sociedade/coronavirus/estudo-brasileiro-mostra-ineficaciade-hidroxicloroquina-azitromicina-em-casos-leves-moderados-de-covid-19-24547361?utm source $=$ notificacao-geral\&utm_medium $=$ notificacao-browser\&utm_campaign $=0 \% 20 \mathrm{Globo}>$. Acesso em: 23 jul. 2020.

MINISTÉRIO DA SAÚDE. Ministério da Saúde divulga diretrizes para tratamento medicamentoso de pacientes. 20 de maio de 2020. Disponível em: <https://www.saude.gov.br/noticias/ agencia-saude/46919-ministerio-da-saude-divulga-diretrizes-para-tratamento-medicamentosode-pacientes>. Acesso em: 16 jul. 2020.

PHILLIPS, Dom. Brazil stops releasing Covid-19 death toll and wipes data from official site. The Guardian, Rio de Janeiro, 07 de junho de 2020. Disponível em: < https://www.theguardian. com/world/2020/jun/07/brazil-stops-releasing-covid-19-death-toll-and-wipes-data-from-officialsite>. Acesso em: 01 jul. 2020.

RICOEUR, Paul. El mal: un desafio a la filosofia y a la teologia. Buenos Aires: Amorrortu, 2007. SOARES, Ingrid. Bolsonaro quer um dia de jejum religioso contra coronavírus. Correio Braziliense, Brasília, 02 de abril de 2020. Disponível em: <https://www.correiobraziliense.com.br/app/ noticia/politica/2020/04/02/interna_politica,842034/bolsonaro-quer-um-dia-de-jejum-religiosocontra-coronavirus.shtml>. Acesso em: 19 jul. 2020.

SÓFOCLES. Antígona. Trad. Donaldo Schüller. Porto Alegre: L\&PM, 1999.

TREZZINA, Martial. OMS encerra em definitivo estudo com hidroxicloroquina para tratamento da covid. Valor Econômico, São Paulo, 04 de julho de 2020. Disponível em: < https://valor.globo. 
com/mundo/noticia/2020/07/04/oms-paralisa-testes-com-lopinavir-e-ritonavir-no-tratamento-decoronavírus.ghtml>. Acesso em: 18 jul. 2020.

URIBE, Gustavo. Mesmo após 6.513 mortes, Bolsonaro diz que crise do coronavírus "não é isso tudo que dizem". Folha de São Paulo, São Paulo, 16 de março de 2020. Disponível em: <https:// www1.folha.uol.com.br/poder/2020/03/mesmo-apos-6513-mortes-bolsonaro-diz-que-crise-docoronavirus-nao-e-isso-tudo-que-dizem.shtml>. Acesso em: 13 jul. 2020. 